\title{
PROPOSIÇÃO DO USO DA METODOLOGIA NET PROMOTER SCORE (NPS) COMO INDICADOR DE DESEMPENHO PARA SUBSIDIAR PLANOS DE MELHORIA CONTÍNUA EM UMA INSTITUIÇÃO EDUCACIONAL
}

\author{
Mayara Tenório de Melo Silva (Centro Universitário UNIFAVIP | WYDEN) \\ mayaratenorioo@gmail.com \\ Morgana Giorgia Costa (Centro Universitário UNIFAVIP | WYDEN) \\ morgana.santos@unifavip.edu.br
}

\section{Resumo}

Devido aos avanços tecnológicos e ao crescimento do acesso à informação, os consumidores vêm desenvolvendo um perfil cada vez mais exigente quando buscam por soluções, produtos ou serviços no mercado. Dessa forma, para uma empresa manter sua competitividade, ela deve superar as expectativas de seus clientes, conhecer o grau de satisfação e lealdade dos mesmos, bem como buscar continuamente fidelizá-los, através do desenvolvimento de planos de melhoria continua. Deste modo, o presente trabalho procurou identificar e analisar as principais falhas decorrentes do modelo e processo de realização da pesquisa de satisfação em uma instituição particular de cursos profissionalizantes. A partir dessas constatações propor o uso da metodologia Net Promoter Score (NPS) como indicador de desempenho, para mensurar o grau de lealdade e satisfação dos alunos, conhecer o nível de alunos Detratores, Promotores e Neutros e a partir disso, ser direcionado planos de melhoria a fim de transformar Detratores e Neutros em Promotores e consequentemente alcançar a zona de excelência do indicador.

Palavras-Chaves: Qualidade em serviços; Melhoria contínua; Net Promoter Score.

\section{Introdução}

Segundo Roman et al.(2012) conhecer os elementos geradores de competitividade, contribui para o aumento da performance organizacional. O estudo desses elementos permite que a empresa busque a utilização das melhores práticas em custos e em qualidade, capturando a necessidade dos consumidores. Através disso, a organização é capaz de obter continuamente melhores desempenhos, condizentes com sua visão, missão e com seus objetivos estratégicos. Como elemento gerador de competitividade importante, a qualidade na prestação de serviços é essencial para o fortalecimento da organização. Isso requisita esforços incessantes, uma vez que faz parte do processo de melhoria contínua da empresa. Alcançar um nível superior de qualidade é possível através de uma boa gestão, contribuindo para eficiência operacional e satisfação do cliente. Para Lacerda (2005, p.20), "qualidade é a filosofia de gestão que procura alcançar o pleno atendimento das necessidades e a máxima satisfação das expectativas dos clientes". 
Este trabalho busca analisar a importância da mensuração do grau de lealdade e satisfação dos alunos em uma instituição educacional particular, sugerindo para isso o uso da metodologia Net Promoter Score (NPS) proposta por Fred Reichheld (2003). A partir dessa proposição, foi realizado com base na ferramenta $5 \mathrm{~W} 2 \mathrm{H}$ um plano de ação com as atividades necessárias para adoção da metodologia, e em seguida realizado um possível plano de melhoria continua para alcance da zona de excelência do indicador NPS, direcionado pelo ciclo PDCA.

\section{Referencial Teórico}

\subsection{Fidelidade, expectativa e satisfação de clientes}

Empresas que buscam continuamente a competitividade direcionam seus esforços em superar as expectativas de seus clientes, contribuindo para a fidelização e satisfação dos mesmos. Estas adotam um modelo de organograma em forma de pirâmide em que os clientes estão no topo (KOTLER e KELLER, 2012).

Figura 1 - Organograma de empresa moderna orientada ao cliente

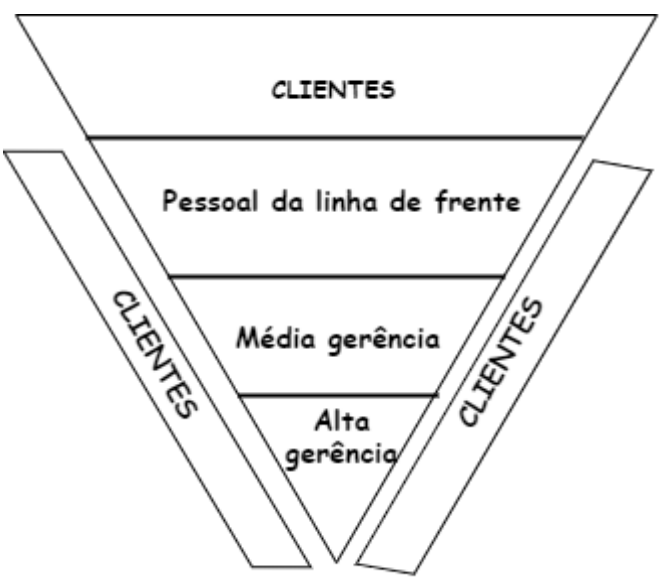

Fonte: Adaptado Kotler e Keller (2012)

Kotler e Keller (2012) abordam que para construção de valor, satisfação e fidelidade do cliente é essencial à adoção do organograma apresentado na figura 1 , o qual trata o cliente como "centro de lucro" da empresa, representando-o no topo da pirâmide seguindo pelo pessoal da linha de frente, adotando o critério de grau de importância, uma vez que, esse pessoal atende os clientes e os satisfaz. Os autores ainda relatam que com o avanço das tecnologias digitais, os consumidores estão continuamente mais informados, logo esperam que as empresas façam mais do que satisfazê-los, mais do que encantá-los.

Silva e Saraiva (2012) destaca como fator de sobrevivência, a fidelização dos clientes, a qual deve ser compromisso desde a missão e cultura das empresas. Satisfação e qualidade, também devem ser tratadas como prioridades base das preocupações organizacionais. Afirma que a 
fidelidade é conquistada em longo prazo e a satisfação pode ser alcançada em uma única transação. Segundo Kotler (2003) "a fidelização à marca se reflete aproximadamente na taxa de retenção dos clientes”. Para Gonçalves (2007) os clientes fiéis são mais propensos a pagar mais pelos produtos e serviços, como também comprar outros itens e usufruir de outros serviços que a organização oferece.

\subsection{Satisfação do cliente e retornos econômicos}

Segundo SEBRAE (2015) diversos são os benefícios obtidos por empresas que se preocupam em medir a satisfação dos clientes, como permitir melhorias e inovações, identificar oportunidade de negócios, fidelizar clientes, identificar prioridades para melhoria de gestão e antecipar comentários em redes sociais.

Ilieska (2013) enfatiza a necessidade que as empresas têm de medir a satisfação dos consumidores, tratando essa satisfação como um ativo que deve ser monitorado e gerenciado, uma vez que, é essencial para o sucesso de qualquer empresa, como também a boa satisfação do cliente possui efeito sobre a rentabilidade de quase todos os negócios.

Para Anderson, Fornell e Lehmann (1994), entender como se associa o nível de satisfação do cliente aos resultados financeiros, são componentes imprescindíveis ao gerenciamento do processo de melhoria da qualidade. Conforme representado na figura 2.

Figura 2 - Como a maior satisfação do cliente levam a retornos econômicos mais altos

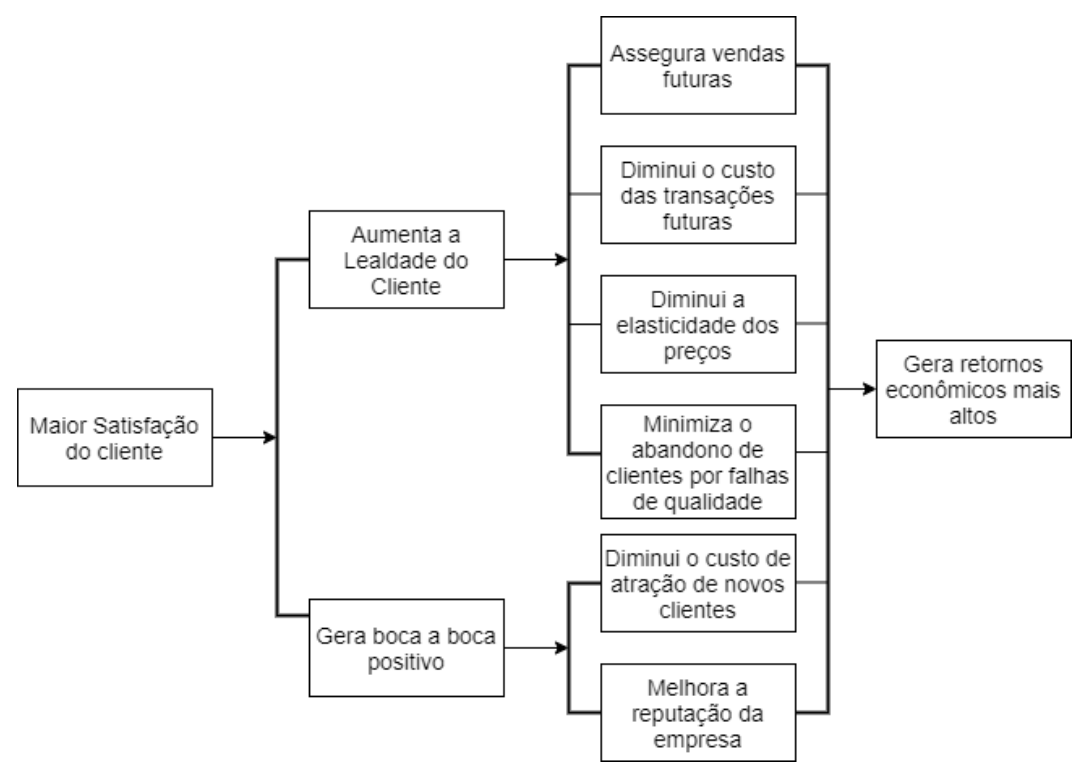

Fonte: Palladini (2002) adaptado de Anderson e Fornell (1999)

De acordo com Reichheld (2003), clientes leais falam de uma empresa aos seus familiares, amigos e colegas. Dessa forma por captar novos clientes - sem custo para a empresa - 
contribuem para o crescimento rentável da mesma, uma vez que, seus clientes leais acabam por se tornar seu departamento de marketing.

\subsection{Qualidade em serviços}

Segundo Lehtinen (1983), serviços podem ser tratados como uma série de atividades que tem lugar nas interações com uma pessoa ou uma máquina física, e que provê satisfação ao consumidor. De acordo com Grönroos (1993), serviços não são coisas, são processos e atividades, onde essas atividades são intangíveis e que as interações presentes em serviços são de importância substancial. Se tratando de qualidade do serviço, Carvalho e Paladini (2012), descreve a seguinte equação: "Qualidade do serviço = serviço percebido - serviço esperado". De acordo com a NBR ISO 9001:2015 a organização deve determinar os métodos para obter, monitorar e analisar a percepção de clientes do grau em que suas necessidades foram atendidas. Através dos dados e informações provenientes do monitoramento e medição, avaliar o desempenho e a eficácia do sistema de gestão da qualidade, bem como a necessidade de melhorias no sistema de gestão. A norma estabelece os seguintes princípios de gestão da qualidade: foco no cliente, liderança, engajamento das pessoas, abordagem de processo, melhoria, tomada de decisão baseada em evidência e gestão de relacionamento.

\subsection{Net Promoter Score (NPS)}

Através de várias pesquisas e estudos, verificou-se que uma única pergunta de pesquisa pode, de fato, servir como um preditor útil de crescimento para uma organização. Trata-se da disposição dos clientes de recomendar um produto ou serviço a outra pessoa, o que diz respeito ao grau de lealdade dos mesmos, capaz de impulsionar o crescimento de primeira linha da organização, uma vez que, os clientes verdadeiramente leais, tendem a comprar mais ao longo do tempo à medida que seus rendimentos aumentam assim se destaca a importância em monitorar a lealdade destes, a fim de se administrar o crescimento lucrativo (REICHHELD, 2003).

Para Marr (2012) é de relevante importância compreender o quão satisfeitos e leais os clientes podem ser e entender como isso é importante para qualquer empresa. Destaca que empresas com altas pontuações de NPS possuem maiores taxas de crescimentos em relação às suas concorrentes. Aborda o NPS como uma métrica simples que detém empresas e funcionários responsáveis pela forma como tratam os clientes e que quando combinados com diagnósticos e ações de acompanhamentos adequados, impulsiona melhorias em fidelização de clientes, permitindo um crescimento rentável para a organização. 
Segundo Reichheld (2003), o NPS é um índice de promotores líquidos e possui como base a pergunta "Qual é a probabilidade de você recomendar [a empresa X] a um amigo ou colega?". Através dos comportamentos de recomendações ao longo da escala, foi possível identificar três grupos lógicos: "Promotor", que são os clientes com as maiores taxas de recompra e encaminhamento e que deram classificações de nove ou dez. "Neutro" os quais classificaram com notas sete ou oito e o "Detrator" que são os clientes que pontuaram de zero a seis. A figura 3 apresenta como é calculado esse indicador.

Figura 3 - Cálculo do Net Promoter Score (NPS)

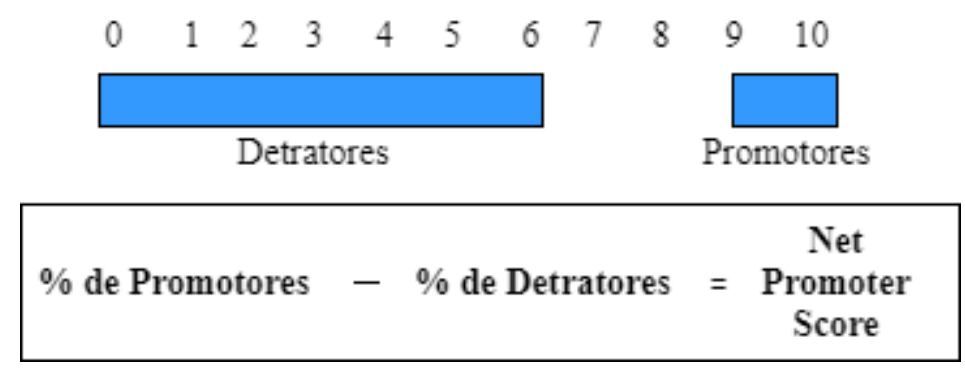

Fonte: Adaptado de Marr (2012)

Um complemento poderoso a única pergunta do NPS é uma ou algumas perguntas abertas, como por exemplo: Qual ou quais as áreas que podem ser melhoradas?. Dessa forma a empresa terá maior suporte para programas de melhorias contínuas. Referente ao cálculo do NPS é realizado com a subtração entre a porcentagem do número de clientes que são promotores (que classificaram entre 9 e 10) e a porcentagem de detratores (que classificaram entre 0 e 6) (MARR, 2012).

\subsection{Ciclo PDCA}

O melhoramento contínuo provém de natureza repetida e cíclica, o que pode ser melhor representado pelo ciclo PDCA (ou roda de Deming), o qual é uma sequência de atividades que devem ser percorridas obedecendo o ciclo, para o seu melhoramento (SLACK, 1996). A NBR ISO 9001:2015 destaca que o Ciclo PDCA qualifica a organização assegurando que seus processos sejam gerenciados adequadamente, identificando oportunidades de melhorias e contribuindo como auxílio na tomada de decisão sobre ações a serem realizadas.

Cada letra da sigla representa uma etapa do método: Planejamento ( $\mathrm{P}$-plan) representa o planejamento detalhado da ação que se pretende implantar, guiado por objetivos quantificados. Execução (D - do) refere-se à implantação efetiva do planejamento. Controle (C - check) é a fase de avaliação, onde é confrontado o planejado com o realizado. Ação (A act) é estabelecido o ciclo de melhoria contínua, onde os resultados alcançados são analisados 
cuidadosamente (CARVALHO \& PALADINI, 2012). Na figura 4 é apresentado o ciclo PDCA.

Figura 4 - Ciclo PDCA para melhorias

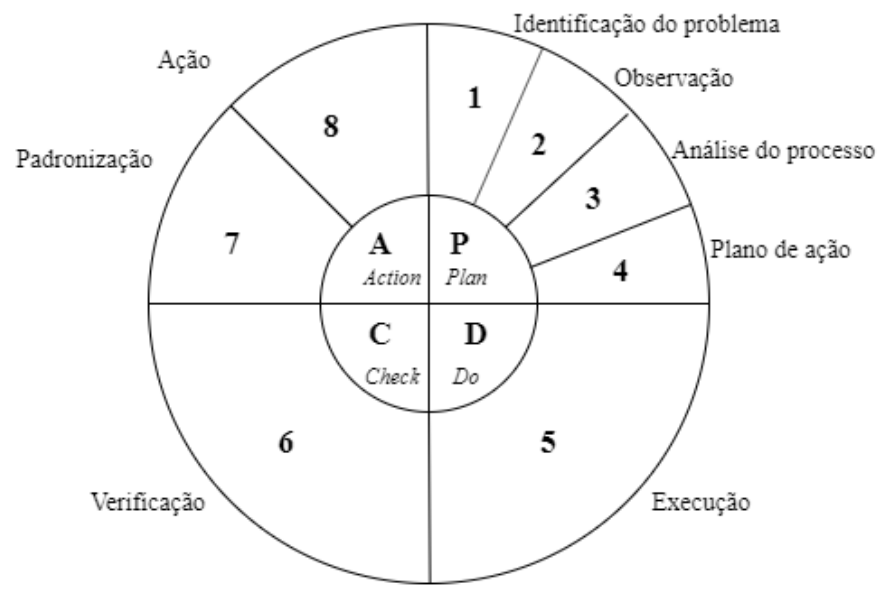

Fonte: Adaptado de Campos (1992).

$\mathrm{Na}$ etapa de planejamento devem ser definidas as metas e as ações necessárias para atingir as metas. Para a competitividade de uma organização, no mínimo se faz necessário que todos sejam exímios solucionadores de problemas. O ciclo PDCA para melhoria é responsabilidade desde o presidente da organização até o nível de supervisor (CAMPOS, 1992).

\subsection{Ferramenta 5W2H}

O 5W2H é uma ferramenta de gestão que funciona como um checklist de atividades, que contribui para a execução e controle das tarefas da organização, tornando um meio produtivo de se desenvolver um projeto, onde todos os envolvidos saberão exatamente o que fazer, quando, onde e etc., resultando em uma sinergia que pode se tornar um importante diferencial estratégico para o negócio (ENDEAVOR, 2017). É uma das ferramentas de gestão mais utilizadas, por ser extremamente útil para as empresas, uma vez que, elimina as dúvidas que possam surgir referentes aos processos e atividades, contribuindo para agilidade na realização das tarefas a serem desenvolvidas (PERIARD, 2009).

A sigla é formada pelas sete diretrizes: What (o que será feito?), Why (por que será feito?), Where (onde será feito?), When (quando será feito?), Who (por quem será feito?), How (como será feito?), How much (quanto vai custar?). As respostas para essas sete perguntas, forma a metodologia 5W2H (TREASY, 2015). 


\section{Metodologia da pesquisa}

Este trabalho possui características descritivas, pois de acordo com Fonseca (2012) descreve uma realidade tal como é manifestada, buscando entendê-la e interpretá-la, possibilitando ao investigador descobrir uma nova percepção a respeito do fenômeno estudado.

A princípio houve um levantamento bibliográfico que procurou realizar um estudo mais detalhado sobre, fidelização e satisfação do cliente, retornos econômicos, Net Promoter Score e como este pode ser utilizado para subsidiar planos de melhorias.

Posteriormente realizou-se um estudo de caso em uma escola particular de cursos profissionalizantes, onde de acordo com Gil (2008) permite ao investigador um conhecimento abrangente e detalhado a respeito de um determinado objeto de estudo, contribuindo para detecção de novas perspectivas a seu respeito.

O presente trabalho aborda o problema na perspectiva quantitativa, uma vez que a metodologia Net Promoter Score através de uma pergunta objetiva obtém respostas em escalas numéricas. Como também características qualitativas, que segundo Fonseca (2012) aborda para esse tipo de método, técnicas específicas como questionários abertos, entrevistas, entre outros.

\section{Aplicação e estudo de caso}

O presente estudo de caso desta pesquisa foi realizado em uma instituição educacional particular de cursos profissionalizantes localizada no Agreste Pernambucano, trata-se de um empreendimento de pequeno porte e que atua na cidade a cerca de 4 anos. Conta com cursos na área de saúde, tecnologia, idiomas e gestão, com projeto em andamento para inclusão em seu portfólio de mais um curso na área de tecnologia. Atualmente são cerca de 1.000 alunos ativos, aproximadamente 50 colaboradores e 10 departamentos.

Na primeira etapa do desenvolvimento deste trabalho, deu-se a análise de como é realizada a pesquisa de satisfação adotada pela instituição e identificação das perguntas inclusas no modelo de pesquisa. A pesquisa atualmente é realizada pelo departamento CRA, com o período de a cada 6 meses, uma vez que que os cursos são ministrados em módulos. A pesquisa é somente realizada por um único meio, que são as ligações. A figura 5 representa esse processo. 
Figura 5 - Fluxograma de realização da pesquisa de satisfação

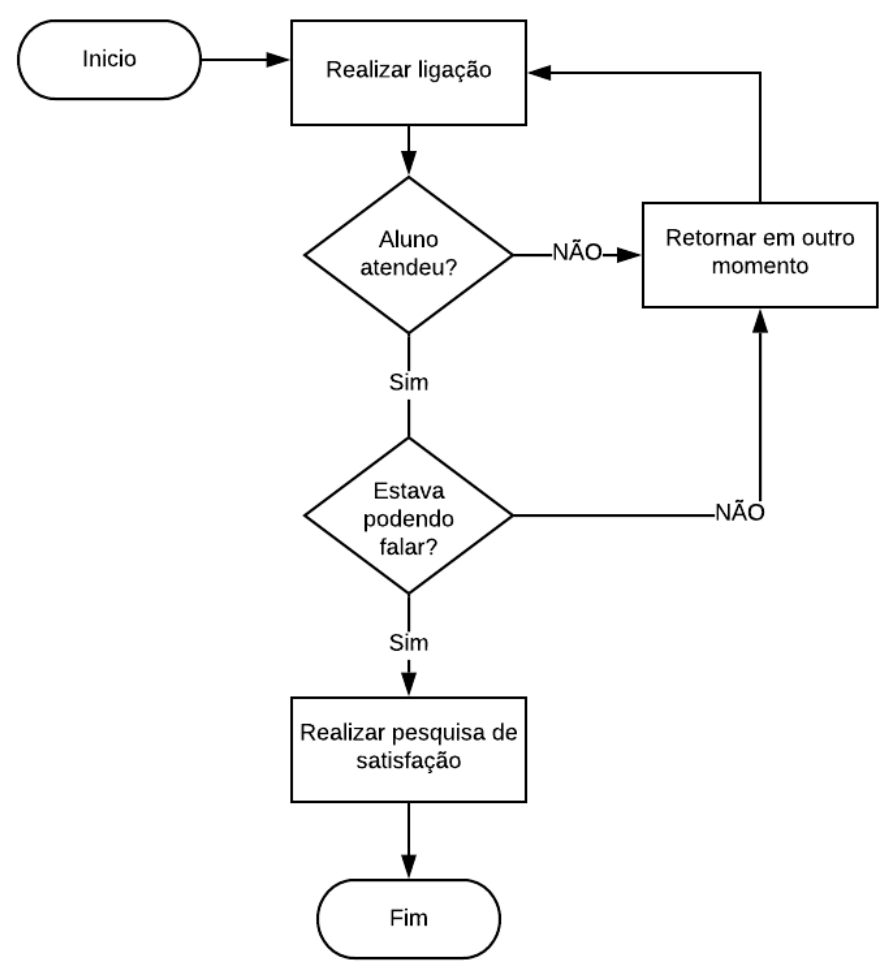

Fonte: A autora (2020)

As perguntas realizadas na pesquisa são as seguintes:

- Qual a sua avaliação para metodologia utilizada pelo professor?

- Qual a sua avaliação para o conteúdo abordado em sala?

- Como você avalia os setores da instituição?

- O que você sugere de melhoria para a instituição?

- De 0 a 10 como você avalia a instituição como um todo?

Pode-se verificar que entre as perguntas abordadas na pesquisa, nenhuma é suficiente para reconhecer o grau de lealdade dos alunos. Não é possível identificar o nível de detratores e neutros e consequentemente não ser gerado um plano eficiente de melhoria na busca de contribuir para fidelização desses alunos e transformá-los em promotores.

\subsection{Falhas encontradas no processo de aplicação e no modelo da pesquisa adotado pela instituição}

Através dessa análise, foi possível identificar algumas falhas referentes à aplicação e ao modelo da pesquisa: 
- Grande probabilidade de não conseguir contato com o aluno;

- O processo de "retornar em outro momento" não tem uma atenção de retorno, ou seja, não é definido um prazo para retornar aquela ligação, passando muitas vezes o contrato esquecido;

- Colaborador designa uma boa parte do seu tempo de trabalho realizando as ligações de pesquisas, atrasando a execução de outras atividades do setor;

- Pelo fato da pesquisa ser realizada por um colaborador da instituição, logo o aluno pode não querer responder quanto a sua real satisfação perante o professor, setores e instituição em geral, levando a uma superficial ou até mesmo falsa avaliação;

Diante das falhas encontradas é verificada a ineficiência no processo de aplicação e no modelo da pesquisa, ou seja, não é possível conhecer a real satisfação dos alunos para com a instituição e consequentemente não obter um plano assertivo de melhoria na qualidade da prestação de serviços.

\subsection{Proposição do uso da metodologia Net Promoter Score (NPS)}

A princípio a escolha da metodologia se deu, pelo fato de ser simples e eficiente quanto à mensuração do grau de lealdade e satisfação dos alunos.

Proporciona uma maior velocidade no ato da pesquisa, uma vez que possui como base uma pergunta objetiva, podendo ter o complemento de uma pergunta subjetiva. Fornece ao entrevistado uma maior liberdade de avaliação e resposta, já que é realizada de forma online, através de E-mail, links e QR Code e por esse motivo também possui maior alcance de entrevistados. Atualmente essa métrica é adotada por diversas empresas de grande e pequeno porte.

A pergunta objetiva utilizada como base para a metodologia é: "Em uma escala de 0 a 10, qual é a probabilidade de você recomendar [a empresa X] a um amigo ou colega?". Inicialmente a pergunta subjetiva sugerida é: "O que podemos fazer para melhorar nossos serviços?”.

Após a realização da pesquisa e de posse dos dados e informações necessárias, é fundamental a elaboração de um plano de ação, para estimulo da melhoria continua da organização, na busca de a cada semestre de realização da pesquisa, obter cada vez mais aumento do NPS, ou seja, aumento da fidelidade e satisfação dos alunos.

Para iniciar a abordagem com os alunos, a figura 6 representa um modelo de pesquisa. 
Figura 6 - Modelo de pesquisa NPS.

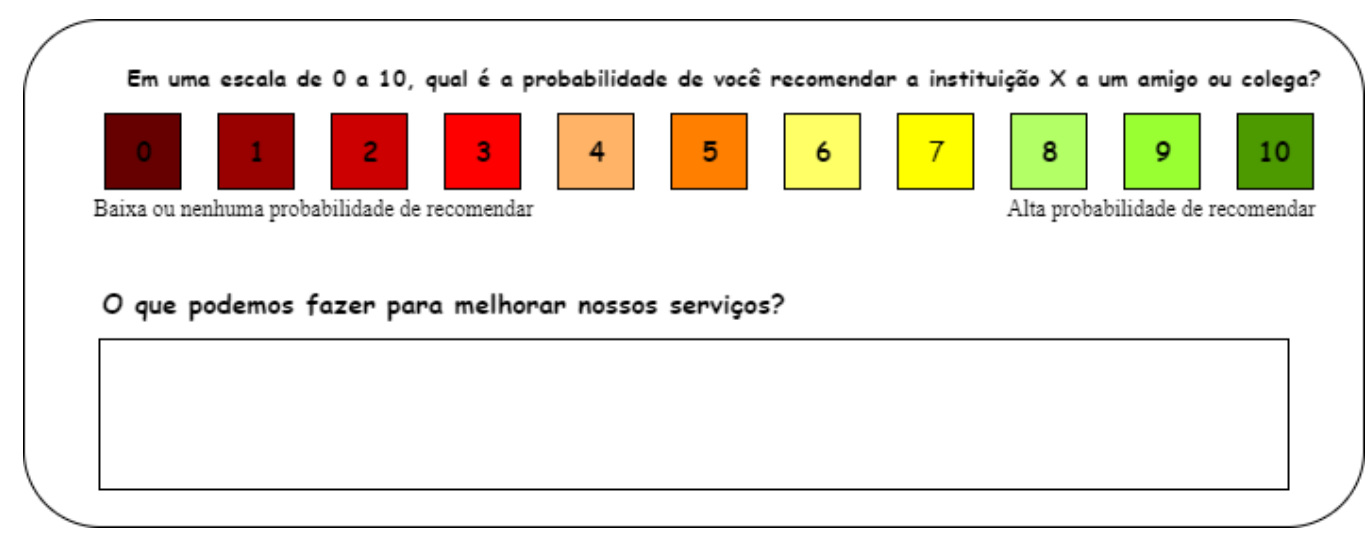

Fonte: A autora (2020)

Com isso é possível à coleta dos dados para cálculo do NPS como apresentado no referencial teórico. De acordo com as pontuações os alunos serão classificados em:

- Promotores (notas 9 e 10): Correspondem aos alunos leais, que realmente são fiéis a organização e recomendam a instituição para todos, dessa forma se tornando o departamento de marketing e contribuindo por acelerar o crescimento da empresa.

- Neutros (notas 7 e 8): Correspondem aos alunos que possuem ressalvas quanto a recomendação da instituição, são indiferentes e possuem facilidades de experimentar os serviços de concorrentes;

- Detratores (notas 0 a 6): São os alunos insatisfeitos, que não possuem uma boa experiência com a instituição, são frustrados e acabam por falar mal da instituição na comunicação boca a boca, como também maior riscos de reclamações em redes sociais, capazes de prejudicar a imagem da empresa.

De acordo com a Tracksale, empresa de tecnologia digital, que auxilia o processo de pesquisa, monitoramento e gestão da satisfação de clientes, a qual presta serviços para grandes empresas, como por exemplo, MRV Engenharia, FIAT, Jeep, Banco Inter, Natura, entre diversas outras, temos a seguinte zona de classificação do NPS:

- Zona de Excelência: NPS entre 76 e 100;

- Zona de Qualidade: NPS entre 51 e 75;

- Zona de Aperfeiçoamento: NPS entre 1 e 50;

- Zona Crítica: - 100 e 0.

O importante para uma organização é sempre obter a cada pesquisa um número maior de NPS, se comparado ao anterior. 


\subsection{Plano de ação para adoção da metodologia proposta}

O plano de ação para adoção do NPS, de acordo com a revisão bibliográfica deste trabalho deu-se por meio da ferramenta $5 \mathrm{~W} 2 \mathrm{H}$ representado na figura 7.

Figura 7 - Plano de ação para proposição do NPS

\begin{tabular}{|c|c|}
\hline & Plano de ação para proposição do NPS \\
\hline O que será feito? & Implantação do Net Promoter Score (NPS) na instituição educacional. \\
\hline Por que será feito? & $\begin{array}{c}\text { A instituição precisa acompanhar o grau de fidelidade de seus alunos, a que } \\
\text { nivel está sendo atendida as expectativas dos mesmos, e fomentar planos de } \\
\text { melhoria continua para qualidade na prestação de serviços. }\end{array}$ \\
\hline Onde será feito? & Na instituição educacional particular de cursos profissionalizantes \\
\hline Quando será feito? & $\begin{array}{c}\text { A pesquisa poderá ser realizada a cada semestre, ou seja, a cada finalização de } \\
\text { módulo das turmas. }\end{array}$ \\
\hline Por quem será feito? & $\begin{array}{c}\text { Os gestores da instituição irá designar um ou mais responsáveis pela } \\
\text { aplicação e acompanhamento da pesquisa, bem como o tratamento dos dados } \\
\text { e geração de informações. }\end{array}$ \\
\hline Como será feito? & $\begin{array}{c}\text { A pesquisa do NPS poderá ser realizada por meio de ferramentas gratuitas de } \\
\text { pesquisas e divulgada através de QR Code em cartazes colacados em salas de aulas } \\
\text { ou links via E-mail e Whatsapp. O tratamento dos dados poderá ser realizado } \\
\text { através da ferramenta Excel. }\end{array}$ \\
\hline Quanto vai custar? & $\begin{array}{c}\text { Impressão de 7 cartazes coloridos, para a divulgação da pesquisa, valor total } \\
\text { máximo RS } 20,00 .\end{array}$ \\
\hline
\end{tabular}

Fonte: A autora (2020)

O plano de ação apresentado para proposição do NPS poderá passar por alterações de acordo com a necessidade da instituição. A princípio como a ferramenta de pesquisa poderá ser meio gratuito, logo os custos envolvidos serão com cartazes para divulgação da metodologia. O tratamento dos dados poderá ser realizado por meio da ferramenta Excel, como também a própria ferramenta gratuita de pesquisa, como por exemplo, a SurveyMonkey é capaz de gerar gráficos estatísticos e relatórios da pesquisa, dessa forma será de grande auxilio para a pessoa designada no momento de apresentar os resultados para os gestores e envolvidos.

\subsection{Plano para possíveis ações de melhoria contínua}

A seguir, com base no ciclo PDCA tratado na revisão bibliográfica, foi realizado um plano com possíveis ações de melhorias para se alcançar a zona de excelência do NPS, como mostrado na figura 8 . 
Figura 8 - Ciclo PDCA para aumento do NPS

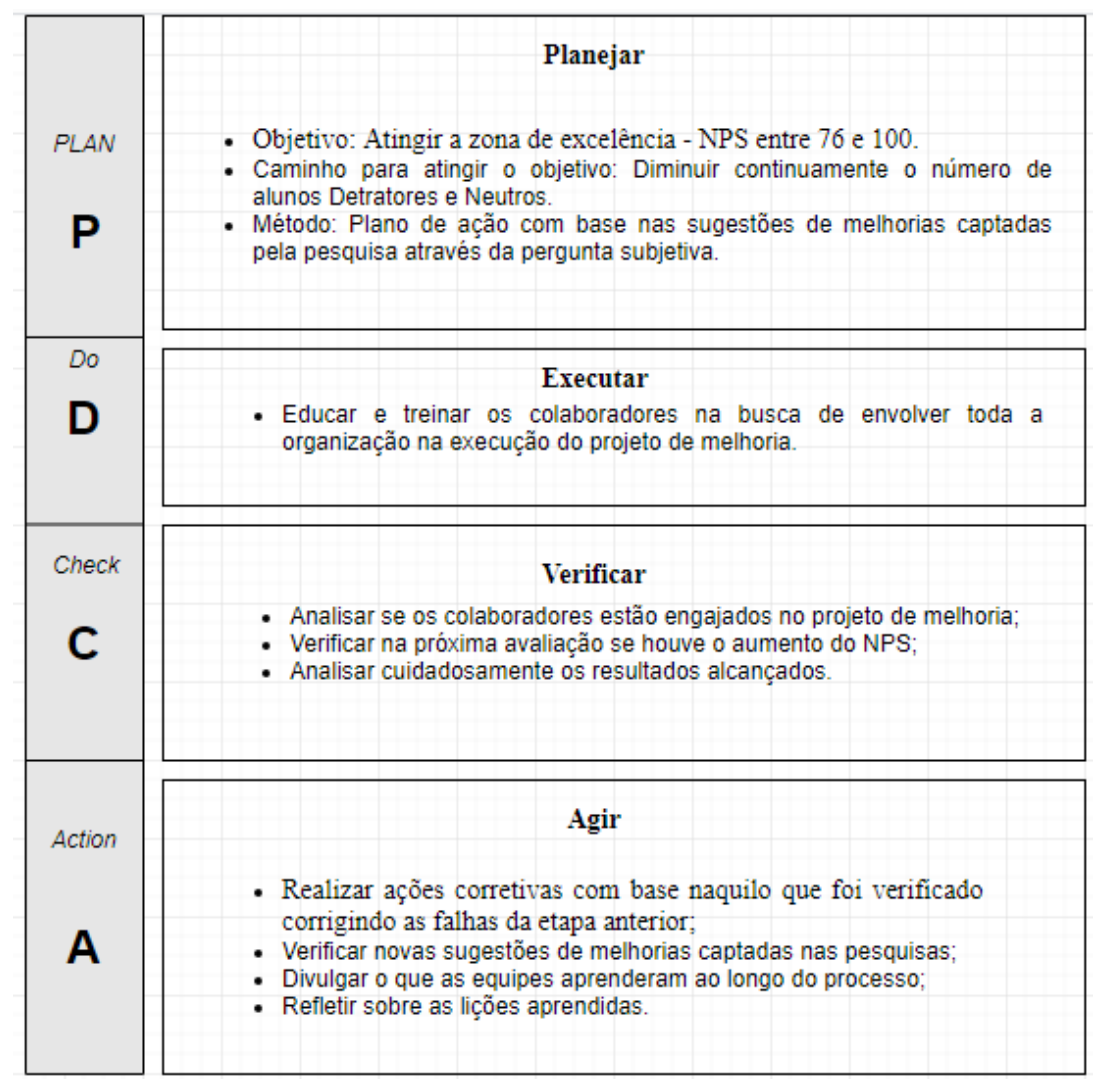

Fonte: A autora (2019)

Para a organização é importante que busque continuamente a melhoria, possuir como objetivo a zona de excelência dada à pontuação do NPS entre 76 e 100. Porém esse é um caminho gradativo, de médio a longo prazo, logo é importante focar em sempre obter um NPS maior do que o calculado anteriormente. É importante também que se estabeleçam metas atingíveis, que proporcione o aumento do NPS no tempo necessário.

\section{5 considerações finais}

É fundamental que as organizações busquem meios de fidelizar seus clientes, como também acompanhar o grau de lealdade dos mesmos, para então conhecer quem são seus clientes Detratores e Neutros a fim de transformá-los em Promotores.

Analisar quem são os alunos Detratores, bem como suas justificativas para a pontuação e a partir disso, trabalhar essas respostas, as causas raízes. Posteriormente traçar um plano para correção de todos os pontos fracos encontrados e executar esse plano. Importante nesse processo o engajamento de todos os colaboradores, a fim de buscar continuamente o aumento de fidelização e satisfação dos alunos, proporcionando uma melhor experiência quanto à qualidade dos serviços prestados. 
É importante destacar que para atingir à zona de excelência não basta somente corrigir as falhas encontradas no processo, é necessário cultivar a cultura de satisfação do cliente na organização, investir na diferenciação, buscar sempre superar as expectativas dos mesmos, que vão além da melhoria contínua do processo.

\subsection{Limitações da pesquisa e trabalhos futuros}

No que se refere às limitações da pesquisa, a principal delas se dá no fato de que não houve a aplicação efetiva da pesquisa do NPS, por esse motivo, não foi possível conhecer a real situação da instituição quanto ao grau de fidelidade de seus alunos, número de Promotores, Detratores e Neutros. Dessa forma não foi possível elaborar um plano melhor direcionado de melhoria.

Quanto aos trabalhos futuros pode-se realizar a implantação da metodologia na instituição dado o plano de ação proposto pelo estudo, realizando-se também a aplicação do NPS aos clientes internos, que são os colaboradores, os quais poderão sugerir melhorias valiosas para o melhor desempenho da organização. 


\section{Referências}

ABNT NBR ISO 9001:2015. Sistemas de Gestão da Qualidade - Requisitos. Disponível em: <http://www.logfacilba.com.br/iso/iso2015_versao_completa.pdf> Acesso em: 11 out. 2019.

ANDERSON, Eugene W.; FORNELL, Claes; LEHMANN, Donald R. Customer satisfaction, market share, and profitability: Findings from Sweden. Journal of Marketing, New York, 1994.

CAMPOS, Vicente Falconi. TQC: Controle da Qualidade Total (no estilo Japonês). FALCONI Editora, 1992. 6 ed.

CARVALHO, Marly Monteiro; PALADINI, Edson Pacheco. Gestão da qualidade: Teoria e casos. Elsevier Editora Ltda, 2012. 2 ed.

ENDEAVOR BRASIL. 5W2H: é hora de tirar as dúvidas e colocar a produtividade no seu dia a dia. Disponível em:<https://endeavor.org.br/pessoas/5w2h/> Acesso em: 12 out. 2019.

FONSECA, Regina Célia Veiga da. Metodologia do trabalho científico. 1 ed. rev. - Curitiba, PR: IESDE Brasil, pg. 54, 2012.

GIANESI, Irineu G. N; CORRÊA, Henrique Luiz. Administração Estratégica de Serviços. Editora Atlas SA, 1994. 1 ed.

GIL, Antonio Carlos. Métodos e técnicas de pesquisa social. 6 ed. São Paulo: Atlas. 2008.

GONÇALVES, Helmer José. Fidelização de clientes. 2007.

GRÖNROOS, Christian. Marketing Gerenciamento e Serviços: A competição por serviços na hora da verdade. Editora Campus, 1993. 14 Tiragem.

ILIESKA, Karolina. Customer Satisfaction Index: as a Base for Strategic Marketing Management. Journal of Marketing, New York, 2013.

KOTLER, Philip. Marketing de A a Z: 80 conceitos que todo profissional precisa saber. Rio de Janeiro: Campus, 2003.

KOTLER, Philip; KELLER, Kevin L. Administração de Marketing. Editora Pearson Education do Brasil, 2012. 14 ed.

LACERDA, F.A.B. Gestão de Qualidade:fundamentos da excelência.Brasília: Sebrae, 2005.

LEHTINEN, J. Asiakasohjautuva palveluyritys (Empresa de Serviços voltada para o Cliente). Espoo, Finlândia: Weilin + Goos, 1983.

MARR, Bernard. Key Performance Indicators: The 75 measures every manager needs to know. Pearson: United Kingdom, 2012. 376 p.

PALLADINI, João S. S. Priorização de Indicadores de desempenho empresarial baseados na satisfação de clientes. Universidade Federal do Rio Grande do Sul, Mestrado Profissionalizante, 2002.

PERIARD, Gustavo. O que é o 5W2H e como ele é utilizado?. Disponível em:<http://www.sobreadministracao.com/o-que-e-o-5w2h-e-como-ele-e-utilizado/> Acesso em: 12 out. 2019.

REICHHELD, Frederick F. The One Number You Need to Grow. Disponível em: $<$ https://hbr.org/2003/12/theone-number-you-need-to-grow> Acesso em: 12 out. 2019.

ROMAN, Darlan José et al. Fatores de competitividade organizacional. BBR-Brazilian Business Review, v. 9, n. 1, p. 27-46, 2012. 
SERVIÇO BRASILEIRO DE APOIO ÀS MICRO E PEQUENAS EMPRESAS. Pesquisa de satisfação: como medir a satisfação dos clientes de pequenos negócios. São Paulo, 2015. Disponível

em: $\langle$ http://www.bibliotecas.sebrae.com.br/chronus/ARQUIVOS CHRONUS/bds/bds.nsf/1e9e80a7b1e4e435ae 5138b511093b8b/\$File/SP comomedirasatisfacao_16.pdf.pdf > Acesso em: 10 out. 2019.

SILVA, Sónia; SARAIVA, Margarida. A Gestão da Qualidade Total como diferencial competitivo na satisfação e fidelização de clientes, 2012.

SLACK, N., CHAMBERS, S., HARLAND, C., HARRISON, A., JOHNSTON, R., Administração da Produção, São Paulo, Atlas, 1996.

TRACKSALE. Pirâmide do NPS. Disponível em: <https://i2.wp.com/satisfacaodeclientes.com/wpcontent/uploads/2016/01/hirarquia-das-notas-net-promoter-score-previa-tracksale-365x1024.jpg?ssl=1> Acesso em: 01 Dez. 2019.

TREASY. O que é 5W2H: reduza incertezas, ganhe produtividade e aprenda como fazer um plano de ação. Disponível em:<https://www.treasy.com.br/blog/5w2h/> Acesso em: 12 out. 2019. 